\title{
Conservation of the hedgehog/patched signaling pathway from flies to mice: induction of a mouse patched gene by Hedgehog
}

\author{
Lisa V. Goodrich, ${ }^{1,3}$ Ronald L. Johnson, ${ }^{1,3}$ Ljiljana Milenkovic, ${ }^{1}$ Jill A. McMahon, ${ }^{2}$ and \\ Matthew P. Scott ${ }^{1,4}$ \\ ${ }^{1}$ Departments of Developmental Biology and Genetics, Howard Hughes Medical Institute (HHMI), Stanford University \\ School of Medicine, Stanford, California 94305-5427 USA; ${ }^{2}$ Department of Molecular and Cellular Biology, The Biological \\ Laboratories, Harvard University, Cambridge, Massachusetts 02138 USA
}

\begin{abstract}
The signaling protein Hedgehog $(\mathrm{Hh})$ controls cell fate and polarizes tissues in both flies and vertebrates. In flies, Hh exerts its effects by opposing the function of a novel transmembrane protein, Patched, while also locally inducing patched (ptc) transcription. We have identified a mouse homolog of ptc which in many tissues is transcribed near cells making either Sonic or Indian hedgehog. In addition, ectopic Sonic hedgehog expression in the mouse central nervous system induces ptc transcription. As in flies, mouse ptc transcription appears to be indicative of Hedgehog signal reception. The results support the existence of a conserved signaling pathway used for pattern formation in insects and mammals.
\end{abstract}

[Key Words: patched; hedgehog; segment polarity; induction; vertebrate development; signaling]

Received November 6, 1995; revised version accepted December 13, 1995.

Intercellular signaling plays a major role in establishing pattern in developing vertebrate embryos. For example, signals from the notochord, a rod of mesoderm along the center of the embryo, induce the floor plate in the adjacent neural tube (Placzek et al. 1990; 1991). The floor plate, a group of morphologically distinct cells in the most ventral region of the neural tube, induces motor neurons and orients commissural axon outgrowth (Tessier-Lavigne et al. 1988; Placzek et al. 1991). A signal from the notochord also appears to determine ventral somite cells to become sclerotome, which will form the axial skeleton (Pourquié et al. 1993). Another signaling center is the zone of polarizing activity (ZPA) in the posterior of the limb buds. The ZPA is able to induce mirror-image duplications of limbs when placed in the anterior limb bud (Saunders and Gasseling 1968) and is believed to normally organize the anterior-posterior axis of the limb bud by causing nearby cells to form posterior structures.

Although the existence of these inductive tissues has been known for years, the molecular identities of the intercellular signals are only now being elucidated. An important step forward was the discovery that the secreted protein Sonic hedgehog $(\mathrm{Shh})$ is produced in several tissues with organizing properties, including the notochord, floor plate, and ZPA (Echelard et al. 1993;

\footnotetext{
${ }^{3}$ These authors contributed equally to this work. ${ }^{4}$ Corresponding author.
}

Krauss et al. 1993; Riddle et al. 1993; Chang et al. 1994; Roelink et al. 1994; Bitgood and McMahon 1995). Misexpression of $S h h$ mimics the inductive effects of an ectopic notochord on the neural tube and somites (Echelard et al. 1993; Fan and Tessier-Lavigne 1994; Johnson et al. 1994; Roelink et al. 1994) and also mimics ZPA function in the limb bud (Riddle et al. 1993; Chang et al. 1994). These studies suggest that $S h h$ is normally responsible for these inductive events.

The Drosophila homolog of Shh, hedgehog $(h h)$, also organizes pattern during development. In the fly, hh establishes the anterior-posterior axis of the embryonic segments and patterns the larval imaginal discs. $h h$ genes encode a secreted protein with a signal sequence (Lee et al. 1992; Mohler and Vani 1992; Tabata et al. 1992) and a region homologous to serine proteases (Lee et al. 1994). A crystal structure of the amino-terminal signaling portion of Shh reveals a zinc hydrolase-like domain as well (Hall et al. 1995).

Hh induces transcription of target genes by opposing the repressive activity of the gene patched (ptc). Ptc is a novel protein with multiple transmembrane domains (Hooper and Scott 1989; Nakano et al. 1989) and is present at the plasma membrane (Capdevila et al. 1994b). Ptc inactivates the transcription of $h h$ target genes such as wingless (wg), a member of the Wnt group (Nusse and Varmus 1992), decapentaplegic (dpp), a transforming growth factor- $\beta$ (TGF- $\beta$ ) family member (Kingsley 1994), 
and $p t c$ itself. In $p t c$ mutants these genes are ectopically activated (Martinez-Arias et al. 1988; Hidalgo and Ingham 1990; Capdevila et al. 1994a), whereas overexpression of $p t c$ represses their transcription (Ingham et al. 1991; Sampedro and Guerrero 1991; Schuske et al. 1994; Johnson et al. 1995). In contrast, $h$ h overexpression causes ectopic embryonic wg expression (Ingham 1993) and ectopic $d p p$ and $p t c$ expression in wing discs (Basler and Struhl 1994; Capdevila and Guerrero 1994; Tabata and Kornberg 1994). Thus, a balance between the opposing activities of these two genes determines the level of target gene expression. Hh may act directly on Ptc as an antagonist (Ingham et al. 1991) or indirectly through a separate signal transduction pathway.

Although the targets of Hh and Ptc vary between tissues, one target that is always induced by $\mathrm{Hh}$ is ptc itself. Low levels of $p t c$ expression in embryos and discs reflect successful Ptc negative autoregulation (Hidalgo and Ingham 1990; Capdevila et al. 1994a). High levels of ptc transcription occur where Ptc is functionally inactivated by the Hh signal. Thus, the most consistent indicator of Hh signaling in flies is the level of ptc transcription.

We have identified a mouse homolog of ptc and demonstrate that $S h h$ and $p t c$ expression are tightly linked during development. Mouse ptc is expressed near Shhproducing cells during early inductive events and next to Indian hedgehog $(I h h)$-producing cells during later limb growth. Like $h h$ in Drosophila, ectopic Shh in the mouse CNS induces ptc transcription in neighboring cells. These results demonstrate the existence of a conserved $\mathrm{Ptc} / \mathrm{Hh}$ signaling relationship in fly and mammalian induction events.

\section{Results}

Identification and characterization of a mouse homolog of ptc

A mouse homolog of ptc was identified by RT-PCR of embryonic limb bud RNA using primers for regions conserved in ptc homologs from several insect species (see Materials and methods|. The full-length coding sequence of mouse ptc was determined by sequencing two overlapping cDNA clones (M2 and $\mathrm{M} 9$ ) isolated from a 8.5 days postcoitus $(\mathrm{dpc})$ embryonic mouse library. Nine other cDNAs were partially sequenced and found to be identical to this ptc homolog. We have not detected additional $p t c$ genes either by low stringency hybridization to genomic DNA, library screening, or degenerate PCR (data not shown).

The M2 and M9 cDNAs (1.9 and $3.0 \mathrm{~kb}$, respectively) comprise $4.6 \mathrm{~kb}$ of contiguous sequence that includes the entire open reading frame of mouse ptc (Fig. 1A). Translation is proposed to begin at the first encountered AUG (nucleotide 97 of M2), as this region (GGCAACAUGG) fits the translational initiation consensus well

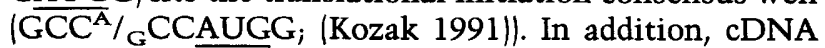
clones for human $p t c$, which have high sequence similarity to the mouse, contain a stop codon upstream of this AUG (data not shown), indicating that this is the initiating methionine for both homologs. The mouse ptc cDNA contains an open reading frame of 1434 codons and, when aligned to fly ptc shares $33 \%$ identity and $43 \%$ similarity. This similarity is evenly dispersed over much of the sequence. However, the carboxyl terminus and an internal region of mouse ptc containing a 54amino-acid insert are relatively divergent. Two potential N-linked glycosylation sites (Hubbard and Ivatt 1981) and eight cysteines are conserved between the mouse and fly $p t c$ genes.

Hydropathy analyses (Kyte and Doolittle 1982) show that mouse Ptc lacks a signal sequence but has 12 hydrophobic regions each long enough to span a lipid bilayer (Fig. 1B). The hydropathy plots for the mouse and fly proteins are remarkably similar, suggesting that the proteins have a conserved topological structure. Mouse Ptc is composed of a pair of tandem sets of six potential transmembrane (TM) domains each. In each set of six, the first TM domain is separated from the following cluster of five TM domains by a hydrophilic region of $\sim 300-400$ amino acids. The two halves of the protein have similar predicted topology but no obvious sequence similarity.

\section{Mouse ptc is transcribed in many embryonic and adult tissues}

The embryonic and adult expression of mouse ptc was examined on RNA blots. A ptc probe hybridizes to an 8-kb transcript in mRNA from developing and adult tissues (Fig. 2). Because the open reading frame is $4.5 \mathrm{~kb}$ long, ptc mRNA contains $\sim 3.5 \mathrm{~kb}$ of untranslated sequence. ptc is expressed at very low levels at $7 \mathrm{dpc}$, is most strongly transcribed between 11 and $15 \mathrm{dpc}$, and persists at moderate levels at $17 \mathrm{dpc}$. In the adult, ptc RNA is abundant in the lung, brain, liver, and kidney. Upon overexposure of the blot, ptc RNA is detected faintly in the heart, skeletal muscle, and testis. ptc transcription is therefore widespread in the embryonic and adult mouse.

ptc is expressed near Shh in axial tissues during development

In flies, $p t c$ is transcribed at high levels in cells that receive $\mathrm{Hh}$ signal. In situ hybridization reveals a similar relationship in mice. Antisense probes from three different parts of the ptc cDNA yield identical results, and no specific staining is observed with a control probe from the sense strand (data not shown). Our observations of Shh expression are in accord with earlier reports (Echelard et al. 1993; Chang et al. 1994; Roelink et al. 1994; Bitgood and McMahon 1995).

Shh and ptc are expressed in neighboring cells from the earliest stages of neurulation. ptc RNA is first detected faintly along the anterior axis of 7.5-dpc embryos at the early head-fold stage (data not shown). By 8 dpc, hybridization is intense down the middle of the head folds, with weak staining in the neuroepithelium extending to the node where Shh is expressed (Fig. 3A,B). Sections of 

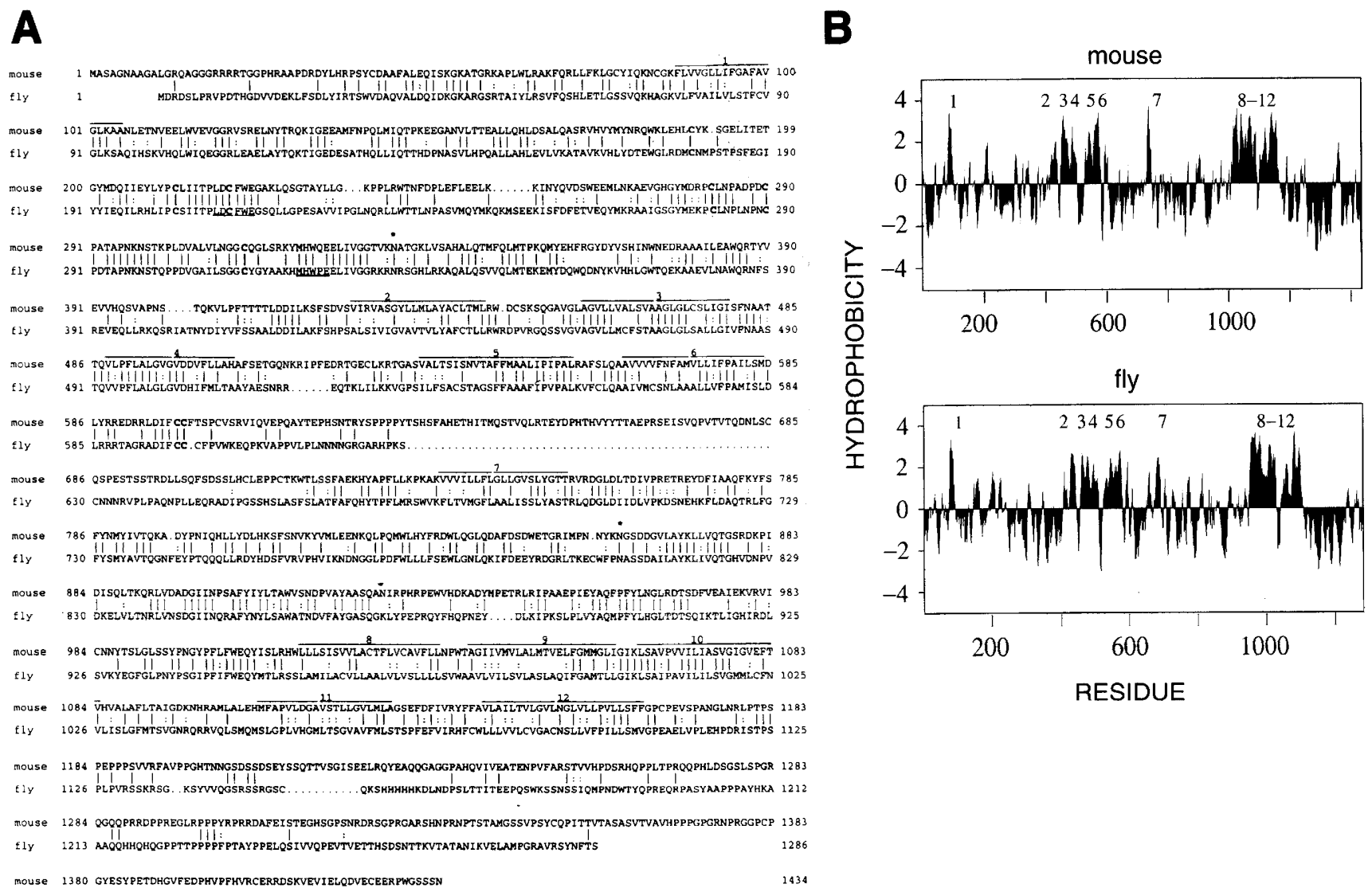

Figure 1. Sequence analysis of the fly and mouse Ptc sequences. $(A)$ Mouse and fly Ptc amino acid sequences were aligned using the GCG program Gap, and showed $\sim 34 \%$ identity and $44 \%$ similarity overall. Vertical bars and colons indicate amino acid identity and similarity, respectively. Putative TM domains are indicated by horizontal bars above the mouse sequence; the six conserved cysteines are shown in bold face type, and the two conserved $\mathrm{N}$-linked glycosylation sites are denoted with asterisks. The ptc sequences used to make the degenerate PCR primers are underlined. $(B)$ The hydrophobicity profiles of mouse and fly Ptc are highly conserved. The amino acid sequences were analyzed on a Kyte and Doolittle plot (MacVector program) with a window of 9 amino acids. The 12 numbered positive peaks indicate potential membrane spanning regions.

hybridized whole mounts show that $p t c$ is transcribed strongly in the ventral-most cells of the neural tube and weakly in the ventral presomitic mesoderm (Fig. 4A). These tissues abut the Shh-expressing chordamesoderm, which forms the head process and notochord (Figs. 3B and $4 \mathrm{~B}$ ).

Slightly later, at 8-8.5 dpc, ptc transcription is generally limited to the midline of the neural tube (Fig. 3C,E), except for two transverse domains of expression in the developing brain (Fig. 3E). ptc RNA continues to be present at low levels in the ventral presomitic mesoderm and is at high levels in the ventral halves of the somites and in the lateral plate mesoderm (Fig. 3E). Shh expression persists in the axial mesoderm and commences in the ventral midbrain in a region thought to be analogous to the floor plate (Fig. 3D,F).

With the onset of $S h h$ transcription in the floor plate, $p t c$ and $S h h$ expression briefly overlap before resolving into a complementary pattern. By day 9 , ptc RNA begins to disappear from the floor plate where $S h h$ is strongly expressed (Fig. 3G,H). Sections through posterior, less developmentally advanced, tissues reveal a gradient of $p t c$ staining in the neural tube. The highest levels are in the floor plate adjacent to the $S h h$-expressing notochord (Fig. 4C,D). Similarly, in the somite ptc is expressed most strongly in the cells close to the notochord, with lower expression levels in more distant cells of the sclerotome (Fig. 4C,E). In more anterior tissues, ptc expression has disappeared from the $S h h$-expressing floor plate but persists in regions along both sides of the floor plate (Fig. 4E,F). Although there may be a brief period when both genes are transcribed in the floor plate, the changes in ptc and Shh transcription occur coordinately, so that the two genes are expressed in complementary regions most of the time. An exception is seen in the hindbrain, where briefly between days 9 and 9.5, strong stripes of ptc staining extend dorsolaterally within each rhombomere (Fig. 3G, inset). Shh RNA remains restricted to the ventral midline cells of the rhombomeres (Fig. 3H; data not shown).

Expression of $p t c$ and $S h h$ does not change much in the spinal cord or somites of 10-dpc embryos (Fig. 3I,J). In the spinal cord, ptc is widely expressed, extending up the sides of the neural tube, whereas Shh expression is lim- 


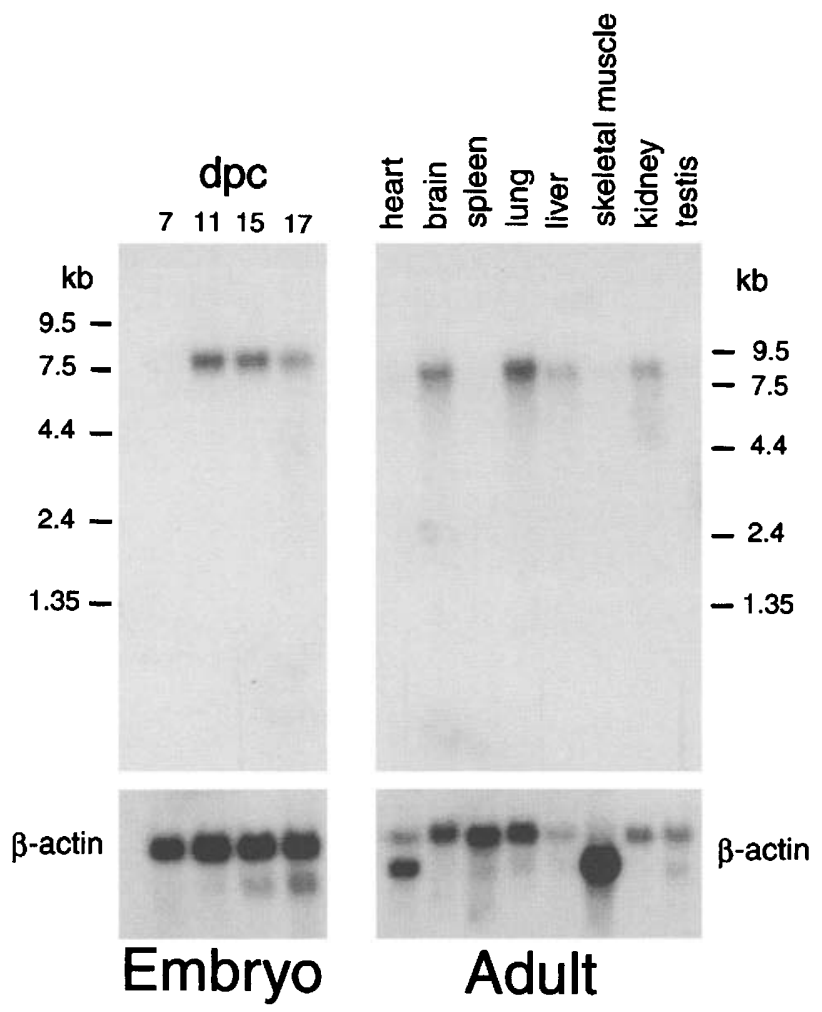

Figure 2. Embryonic and adult expression of the mouse ptc transcript. Blots of poly(A) RNA from embryonic and adult mice were hybridized with ptc (top panels) or human $\beta$-actin probes (bottom panels). $\beta$-Actin mRNA, which has two alternatively spliced transcripts, controls for the loading of the lanes.

ited to the floor plate and notochord. By this stage, $p t c$ transcripts are eliminated from the floor plate along the entire anterior-posterior axis. In the brain, ptc transcripts are largely confined to the ventral midline, except for a region in the diencephalon. Here, ptc RNA is detected in two ventrolateral stripes on either side of the midline (Fig. 3I, red arrows) where Shh transcription expands laterally (Fig. 3J).

ptc and Shh transcription patterns continue to be tightly associated in the nervous system of older embryos. In situ hybridization to sagittal halves of 11.5- to 13.5-dpc brains reveals ptc transcription in the ventricular zone and the zona limitans interthalamica, a molecularly defined boundary between the dorsal and ventral thalamus (Puelles and Rubenstein 1993). ptc RNA accumulates in two lines flanking the zona limitans, whereas $S h h$ RNA is detected clearly along the zona limitans itself (Fig. 5E,F).

\section{ptc and Shh in other developing tissues}

In addition to these axial tissues, ptc and Shh are expressed near each other in the developing gut and follicles. Both ptc and Shh are found in the foregut of 8.5-dpc embryos (Fig. 3C,D) and in the foregut and hindgut of 9-dpc embryos (Fig. 3G,H). Sections through the gut show that ptc RNA is present in both the endoderm and mesoderm while $S h h$ expression is restricted to the ventral endoderm (data not shown). However, by $13.5 \mathrm{dpc}$, ptc RNA is limited to the mesoderm, adjacent to $S h h$ RNA in the endoderm (Fig. 5A-D). ptc and Shh are also found in complementary sites in the hair and whisker follicles, where beginning on day $12.5 \mathrm{ptc}$ is expressed in rings surrounding a central domain of $S h$ (Fig. 5A,B). Other regions of ptc expression include the branchial arches (Fig. 3G,I), palate, tongue, toothbuds, and genital eminence (data not shown).

\section{ptc is transcribed adjacent to two hh family members during limb development}

$p t c$ transcription in the limb bud corresponds to the expression patterns of two hh homologs, Shh and Ihh. ptc RNA is first detected at the posterior edge of the forelimb bud on day 9.5. This expression becomes stronger and broader by $10.5 \mathrm{dpc}$ (Figs. 3I and 6A) Low levels of ptc RNA are present in a similar position in the less advanced hindlimb (data not shown). By $10.5 \mathrm{dpc}$, strong Shh transcription appears in the posterior mesenchyme of the forelimb bud (Fig. 6B). This site of expression presumably corresponds to the murine $\mathrm{ZPA}$, since in chicken embryos Shh products are located in the ZPA (Riddle et al. 1993). Widespread ptc staining persists in the posterior half of 11-dpc limb buds, partially overlapping with Shh RNA in the most posterior mesenchyme (Fig. 6C,D). At $11.5 \mathrm{dpc}$, ptc expression fades in a distal domain near the edge of the limb bud (Fig. 6E). Low levels of $S h h$ are still present in a narrow band of cells in the posterior (Fig. 6F). At no time is ptc RNA found in the apical ectodermal ridge (AER), which is a critical signaling source for maintenance of limb outgrowth (Summerbell 1974). In 12.5- and 13.5-dpc embryos ptc is transcribed in cells adjacent to a source of a second $h h$ family member, Ihh. At this stage, ptc RNA is detected in the periphery of the digital condensations and later in the perichondrium surrounding the hypertrophic digit cartilage (Fig. 6G). Ihh is transcribed in digital condensations neighboring the $p t c$-expressing cells (Fig. $6 \mathrm{H}$ ), but $S h h$ is absent after $12.5 \mathrm{dpc}$ (Fig. $5 \mathrm{~B}$ ). Whereas ptc and $S h$ are transcribed together early in limb bud development, the expression of $p t c$ correlates with Ihh transcription during cartilage differentiation.

\section{ptc is expressed ectopically in Strong's Luxoid mice}

Mice homozygous for the semidominant mutation Strong's Luxoid $\left(1 s t^{D}\right)$ develop extra digits on their foreand hindlimbs. Although the product of the $1 s t^{D}$ locus is unknown, the limb phenotype appears to be caused by an ectopic Shh-expressing ZPA in the anterior of the limb bud (Chan et al. 1995). This ectopic expression of $S h h$ is stronger in the hindlimb than the forelimb. If $p t c$ is downstream of Shh signaling in the limb bud, then ptc should also be expressed ectopically in $1 s t^{D}$ mice.

Homozygous $1 s t^{D}$ embryos $(11.5-12 \mathrm{dpc})$ were identi- 


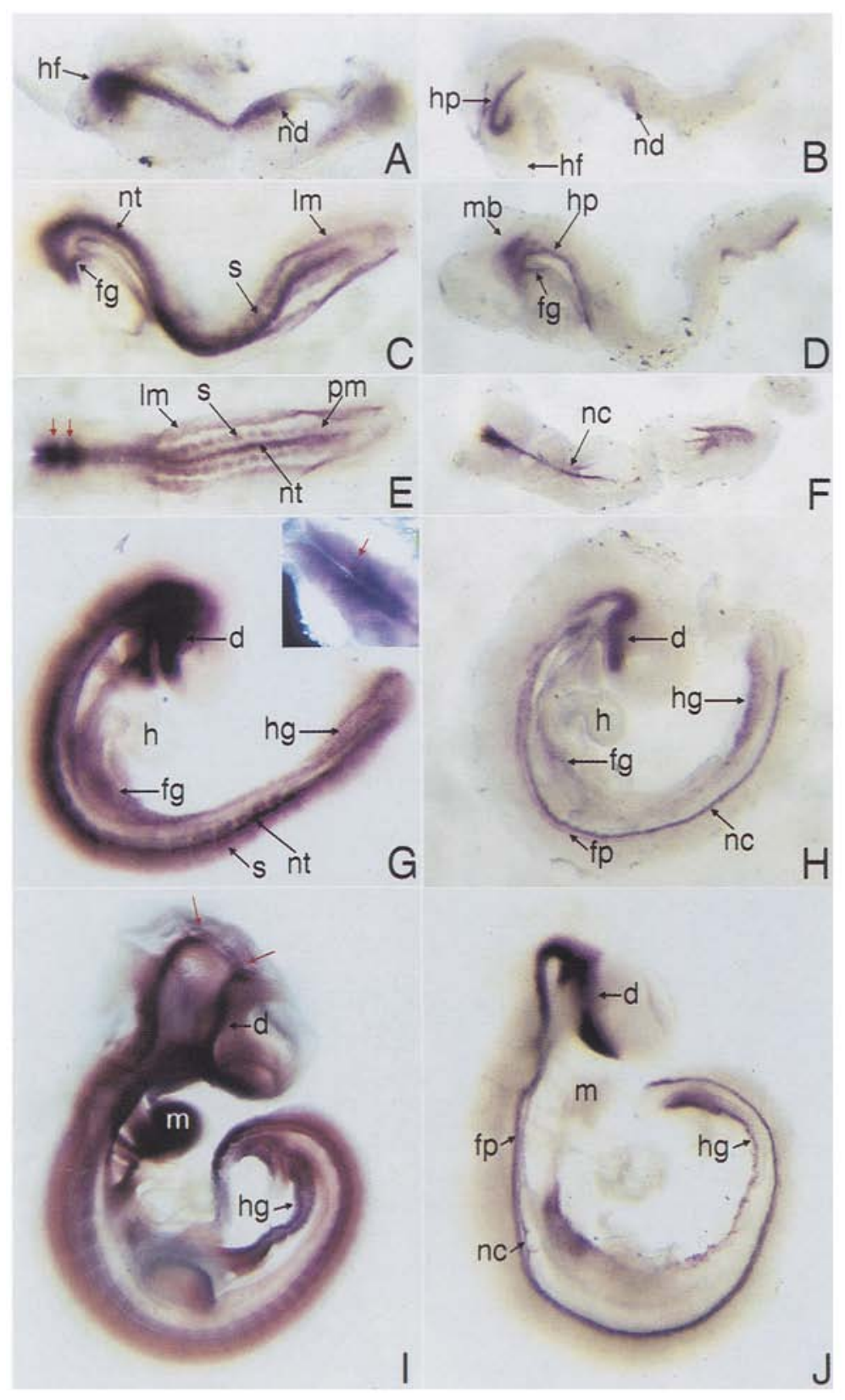

Figure 3. In situ hybridization of $p t c$ and Shh probes to mouse embryos. Mouse embryos were hybridized with probes to ptc $(A, C, E, G, I)$ and $S h h(B, D, F, H, I)$. All views are lateral except $A$, which is ventrolateral, and $E$ and $F$, which are ventral. $(A-F)$ Anterior is to the left. The developmental stages are $8 \mathrm{dpc}$, presomitic $(A, \mathrm{~B})$; $8.5 \mathrm{dpc}, 8-10$ somites (lateral $C, D$; ventral $E, F)$; $9 \mathrm{dpc}, 15-20$ somites $(G, H) ; 9.5 \mathrm{dpc}$ (inset, $G$ ) and 10.5 dpc, 30-40 somites $(I, I)$. The red arrows in $E$ point to transverse expression of $p t c$ in the developing brain. The inset in $G$ is a dorsal view of the hindbrain, with rhombomere expression indicated by the red arrow. In $I$, the red arrows demarcate the ventrolateral expression of ptc in the midbrain. (d) Diencephalon; (fp) floor plate; (h) heart; (hf) head fold; (fg) foregut; (hg) hindgut; (hp) head process; ( $\mathrm{lm}$ ) lateral mesoderm; (m) mandibular arch; (mb) midbrain; (nc) notochord; (nd) node; (nt) neural tube; $(\mathrm{pm})$ presomitic mesoderm; (s) somite. fied by the presence of ectopic outgrowths on all four of their limbs and were examined by in situ hybridization with the ptc probe. In each mutant limb, ptc RNA is found in the proximal region of the anterior outgrowths, as well as in the normal posterior domain (Fig. 6I,J). Like Shh, ectopic ptc is transcribed most strongly in the hindlimbs, at levels comparable to normal ptc expression whereas ectopic ptc signal is weak in the forelimbs. Thus, ectopic expression of $p t c$ in $1 s t^{D}$ embryos correlates with ectopic expression of $S h$.

\section{Ectopic Shh induces ptc in the CNS}

The tight spatial and temporal correlation between the expression of $p t c$ and $h h$ homologs in wild-type and mu- tant mice suggests that, as in flies, Hh induces transcription of the ptc gene. Ectopic expression of chick Shh under the control of a Wnt-1 enhancer was found previously to cause the activation of ventral gene expression in the dorsal CNS (Echelard et al. 1993). We now show that ptc also is expressed ectopically in Wnt-1-Shh transgenic embryos.

Ventralization of the dorsal CNS is strongest in the midbrain and rostral hindbrain (myelencephalon), presumably reflecting the early activation of Wnt-1 in these regions of the brain (McMahon et al. 1992). Some embryos appear to develop a morphologically normal ectopic dorsal floor plate (asterisk in Fig. 7A). Whereas most transgenic embryos ectopically expressing the transgene have a similar phenotype, an open midbrain 


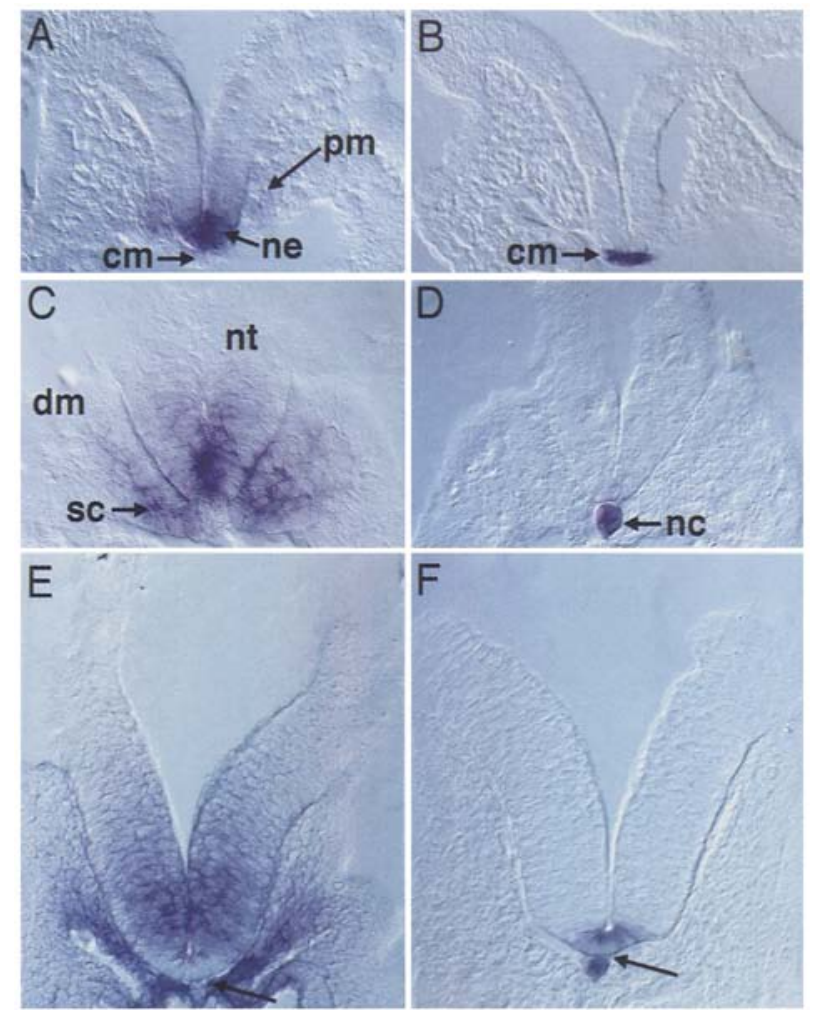

Figure 4. Heterogeneous and dynamic expression of $p t c$ in the neural tube and somites. Transverse sections through embryos hybridized with probes for ptc $(A, C, E)$ and Shh $(B, D, F)$ are shown for the 8-dpc presomitic region $(A, B)$, the 9.5-dpc tail region $(C, D)$, and the 9.5 -dpc midgut region $(E, F)$. The arrows indicate the floor plate and notochord in both $E$ and $F .(\mathrm{cm})$, Chordamesoderm; (dm) dermomyotome; (pm) paraxial mesoderm; (nc) notochord; (ne) neuroepithelium; (nt) neural tube; (sc) sclerotome.

and rostral hindbrain with overgrowth and kinking in the dorsal spinal cord, they vary in the expression of ventral markers.

In 10.5-dpc embryos with strong phenotypes, both $\mathrm{He}$ -

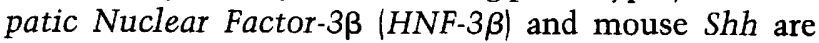
activated at the dorsal /which is lateral before neural tube closure/ midline where Wnt-1 is normally expressed (short arrow in Fig. 7A,B). In addition to normal ptc expression just dorsal to $S h h$ and $H N F-3 \beta$ in the floor plate (long arrow in Fig. 7C), ectopic ptc expression is detected adjacent to, but not overlapping, the sites of ectopic floor plate development (short arrow in Fig 7C). These results are consistent with floor plate-mediated induction of $p t c$ expression by Shh.

In most transgenic embryos, full ectopic floor plate development does not occur. In these embryos $H N F-3 \beta$ is expressed ectopically, but $S h$ is not (Fig. 7D,E,G,H). Interestingly, ectopic ptc expression is observed, adjacent to (Fig. $7 F$ ) or overlapping ectopic $H N F-3 \beta$ expression (Fig 7I). Thus, chick Shh activates $H N F-3 \beta$ locally, probably in the same cells that express the transgene, whereas $p t c$ expression is induced at a distance. Higher levels of Shh may be required for induction of $H N F-3 \beta$ compared to ptc, consistent with the fact that different cell fates are determined by different concentrations of Shh protein (Roelink et al, 1995).

\section{Discussion}

The pattern of mouse ptc transcription supports the existence of a conserved signaling pathway with at least two $h h$ genes as inducing signals and a single $p t c$ gene as a target. ptc is expressed most highly in cells close to Shh-expressing cells. The dynamic pattern of ptc transcription follows closely changes in Shh expression during development so that transcripts of the two genes are found mostly in adjacent, nonoverlapping tissues. Furthermore, Shh is able to activate $p t c$ transcription in the mouse CNS, implying that high levels of $p t c$ transcription in other developing tissues are also induced by cells expressing one of the $h h$ family members. Because the relationships between these mouse genes are much like hh modulation of ptc expression during Drosophila development, similar signaling mechanisms may be employed in mammals and insects.

\section{ptc expression reflects regulation by Shh}

In flies, Hh increases $p t c$ transcription levels by preventing negative autoregulation of $p t c$ itself, thereby causing $p t c$ to be transcribed strongly in cells nearest the $\mathrm{Hh}$ signal. The intense expression of ptc in Shh- and Ihhresponsive tissues is consistent with both genes regulating ptc expression. For example, in 9- to 9.5-dpc embryos, $p t c$ is expressed throughout the ventral two-thirds of the neural tube but at particularly high levels in the floor plate that contacts the $S h h$-expressing notochord. Similarly, ptc staining is strongest near the ZPA in the limb and near the notochord in the somites. In addition to these sites of high transcription, ptc appears to be expressed at low levels throughout most tissues, as the background staining observed in embryos hybridized with the antisense probe is not observed with the sense or other control probes (data not shown). We propose that as in flies, the elevation of high ptc levels in mouse embryos may be attributable to Shh inactivation of Ptc activity, leading to $p t c$ derepression.

Two experiments suggest that $S h h$ induces these high levels of $p t c$ RNA in adjacent cells. First, the $1 s t^{D}$ mutation, which causes a second ZPA and high Shh levels to develop in the anterior of the limb buds /Chan et al. 1995), leads to ectopic ptc transcription. Second, ectopic expression of Shh in the dorsal neural tube activates ptc transcription. Although it is unclear whether Shh induces ptc transcription directly or through secondary signals, it is intriguing that this relationship exists in mice, as a balance in the expression levels of these two genes is crucial for correct gene expression in flies (Johnson et al. 1995). Additional experiments are under way to determine whether mouse Ptc opposes Shh induction of target genes.

As in flies, ptc seems to be a unique target of Shh 

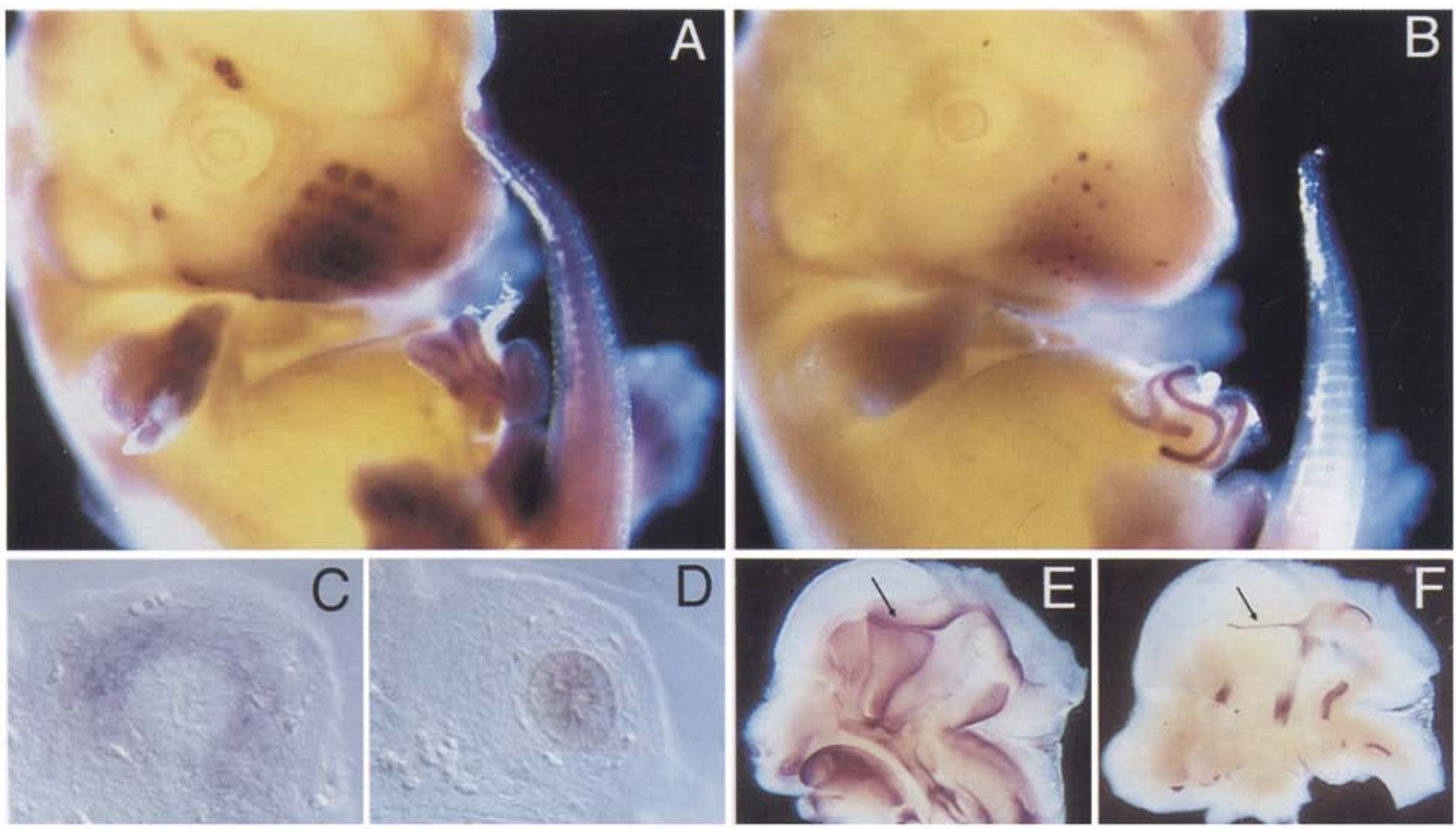

Figure 5. Expression of $p t c$ and $S h h$ later in development. Embryos $(13.5 \mathrm{dpc})$ were hybridized with probes to $p t c(A)$ and $S h h(B)$ and then sectioned to examine the gut expression of $p t c \mid C)$ and $\operatorname{Sh} h(D)$. Brains from 13.5-dpc embryos were cut sagittally and hybridized with probes to $p t c(E)$ and $S h h(F)$. The arrows indicate the zona limitans in $E$ and $F$.

signaling. Several other genes are activated by Shh, but $p t c$ is the only known target gene expressed near all $\mathrm{Hh}$ sources. Furthermore, in the CNS, ptc induction is more sensitive than induction of another Shh target gene, $H N F-3 \beta$. ptc transcription thus appears to be a general indicator of Shh signaling. If this is true, then the gradient of $p t c$ transcription normally observed along the dorsoventral axis of the neural tube may reflect the control of cell differentiation by graded levels of $\mathrm{Hh}$ (Roelink et al. 1995). ptc and hh homologs are coexpressed in many tissues patterned by inductive interactions, so this conserved $\mathrm{Hh}-\mathrm{Ptc}$ pathway may be a general mechanism for cell-cell communication during development. The basis for tissue-specific responses to $\mathrm{Hh}$ and Ptc signaling remains to be explored.

\section{ptc may respond to multiple hh genes}

$p t c$ is expressed near three different $h h$ homologs during development, suggesting that ptc is a common target of multiple $\mathrm{Hh}$ signaling pathways. For example, the expression of $I h h$ and ptc in adjacent tissues during cartilage differentiation suggests that $p t c$ responds to $I h h$ as well as to Shh. ptc is also expressed at the same time as Desert hedgehog $(D h h)$ in the germ line (Bitgood and McMahon 1995). The one site of ptc expression that does not correlate with transcription of known $h h$ genes is in the rhombomeres of 9- to 9.5-dpc embryos (Fig. 3G; Bitgood and McMahon 1995). Because ptc expression is tightly linked to the expression of $h h$ homologs else- where, the presence of ptc RNA in the rhombomeres may indicate an unidentified $h h$ family member that is transcribed away from the midline. Alternatively, ptc may have some Hh-independent functions. Although there may be multiple $p t c$ genes, only single genes have been found in mouse, chick, and human despite hybridization searches at low stringency (this work; Marigo et al. 1996; R.L. Johnson, L.V. Goodrich, and M.P. Scott, unpubl.).

\section{Additional components of the Hh signaling pathway may be conserved between flies and vertebrates}

In flies, cubitus interruptus $\langle c i|$, which encodes a zinc finger-containing protein (Orenic et al. 1990), is an activator of $p t c$ transcription and is required for Hh signaling (Forbes et al. 1993). Hh signaling elevates Ci protein levels post-transcriptionally (Motzny and Holmgren 1995; Slusarski et al. 1995), whereas ptc has the opposite effect (Johnson et al. 1995). As in the fly, where ptc and ci are expressed in many of the same cells, mouse Gli, a cirelated gene, and to a lesser extent, Gli2 and Gli3, are transcribed in ptc-expressing tissues (Hui et al. 1994). ci and its homologs all contain five zinc finger domains (Kinzler et al. 1988; Orenic et al. 1990; Hui et al. 1994) and may act as transcription factors, as human Gli binds specific DNA sequences (Kinzler and Vogelstein 1990). Gli could activate ptc transcription in response to a Shh signal.

Another conserved component of the Hh-Ptc pathway 


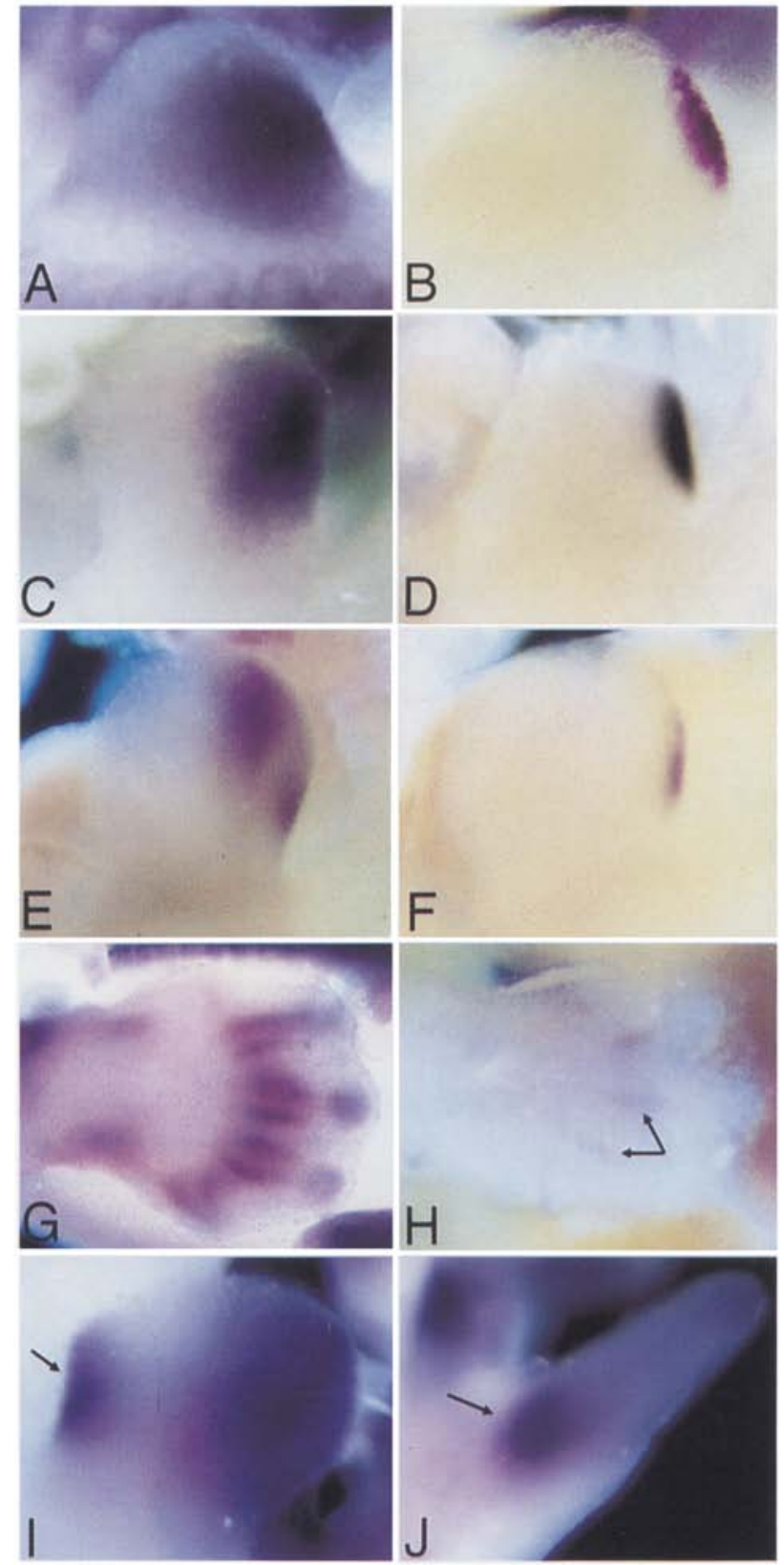

Figure 6. ptc is expressed near $S h h$ and $I h h$ in the limb buds of wild-type and $1 s t^{D}$ mice. Whole-mount wild-type $(A-H)$ or $1 s t^{D}$ $(I, \Pi)$ embryos were hybridized with probes for ptc $(A, C, E, G, I, I)$, $\operatorname{Shh}(B, D, F)$, and $I h h(H) . A-F$ and $I$ are dorsal views with anterior to the left $G$ and $H$ are dorsal views with anterior $u p ; ~ I$ is an anterior view with proximal toward the left. Developmental stages are $10.5 \mathrm{dpc}\langle A, B\rangle, 11 \mathrm{dpc}\langle C, D\rangle, 11.5 \mathrm{dpc}\langle E, F\rangle$, and 12.5 $\operatorname{dpc}(G, H)$ for forelimbs and $11.5 \mathrm{dpc}$ for hindlimbs $(I, J)$. In $H$, the arrows indicate two $\mathrm{Ih} h$-expressing condensations. Ectopic ptc is indicated by the arrows in $I$ and $I$.

is the cAMP-activated protein kinase A (PKA). Like ptc, PKA negatively regulates $d p p, w g$, and $p t c$ transcription and $c i$ protein levels, and is genetically downstream of hh (Jiang and Struhl 1995; Johnson et al. 1995; Lepage et al. 1995; Li et al. 1995; Pan and Rubin 1995; Strutt et al.
1995). Similarly, PKA antagonizes Shh signaling during development of the somites and neural tube (Fan et al. 1995; Hynes et al. 1995). Because the relationship between ptc and PKA is not well understood in flies, it is uncertain how these genes interact in vertebrates.

\section{Possible Ptc protein functions}

The sequence analysis and hydropathy plot leads to a possible model of mouse Ptc (Fig. 8). The two conserved glycosylation sites and the six conserved cysteines suggest that the two large hydrophilic loops are extracellular, whereas the amino and carboxyl termini and the central hydrophilic loop are cytoplasmic. Neither the amino acid length nor the composition of the proposed intracellular domains is well conserved except near the membrane. In contrast, the 12 putative transmembrane domains and the extracellular loops are more highly conserved, suggesting that important functional domains of the protein reside within or outside the plasma membrane.

Ptc has been proposed as a receptor for $\mathrm{Hh}$ protein (Ingham et al. 1991), but the structure suggested by the sequence conservation does not resemble known receptors. Instead, the topology suggests that Ptc is related to transporters that contain 12 transmembrane domains grouped into $6+6$ arrays. These transporters facilitate the movement of small molecules such as sugars, ions, or small peptides across the membrane. The Ptc proteins lack the ATP binding cassette $(A B C)$ that is characteristic of one $6+6$ family, the $A B C$-type transporters, which include the multidnug resistance transporter, and the cystic fibrosis gene CFTR (Doige and Ames 1993; Saier 1994). If Ptc is a novel transporter or channel, the regulatory relationships imply that movement of small molecules through Ptc causes repression of target genes.

\section{Why is ptc induced by $H$ h?}

In Drosophila, a peculiar aspect of the Ptc-Hh relationship is the boosting of Ptc protein levels in cells where Ptc function seems to be eliminated by the Hh signal. This mechanism is probably conserved in vertebrates, as Shh also induces high levels of $p t c$ expression in adjacent cells. Why should th signaling stimulate production of large amounts of inactive protein? In Drosophila, Hh distribution is broader in ptc mutant embryos (Taylor et al. 1993), suggesting that Ptc restricts the movement of the Hh protein. A high level of Ptc could sharpen and delimit the region where target genes are induced by $\mathrm{Hh}$ by blocking or lowering further $\mathrm{Hh}$ movement.

Alternatively, Ptc protein may be active in the cells where high levels are induced, but its activity masked by a competing, antagonistic pathway under the control of Hh. In this model Ptc buffers Hh signaling by maintaining a basal level of negative transcriptional regulation that can be overcome only by large amounts of Hh protein interacting with a separate receptor. Induction of high Ptc levels by Hh may raise the threshold for tran- 
Shh
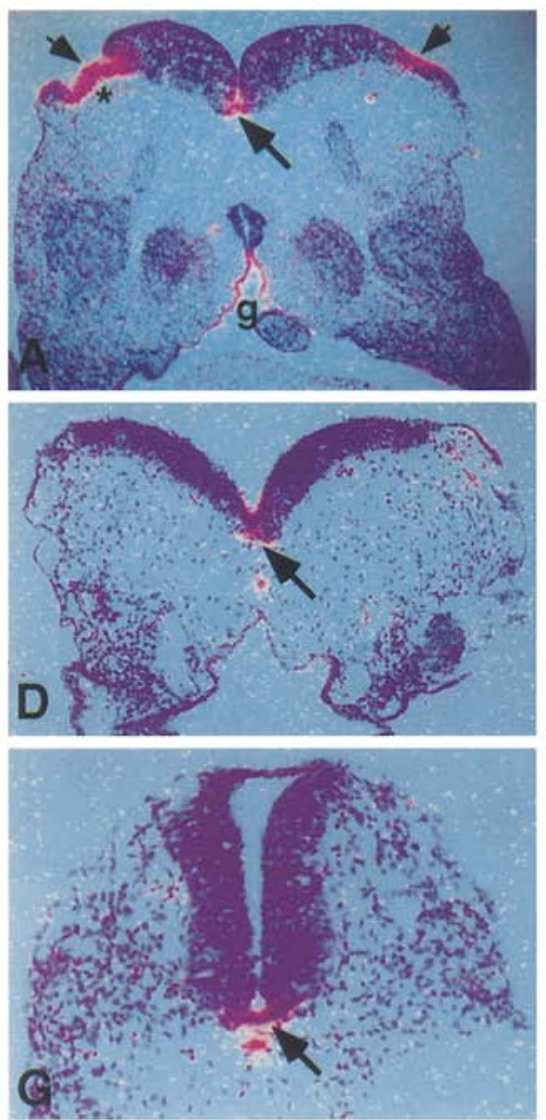

Hnf-3ß
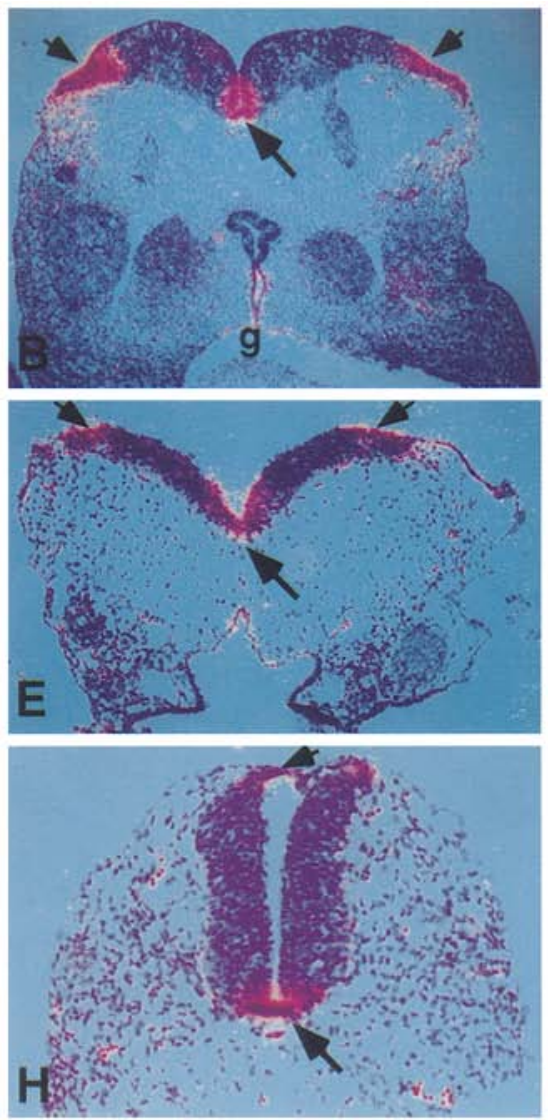

Ptc
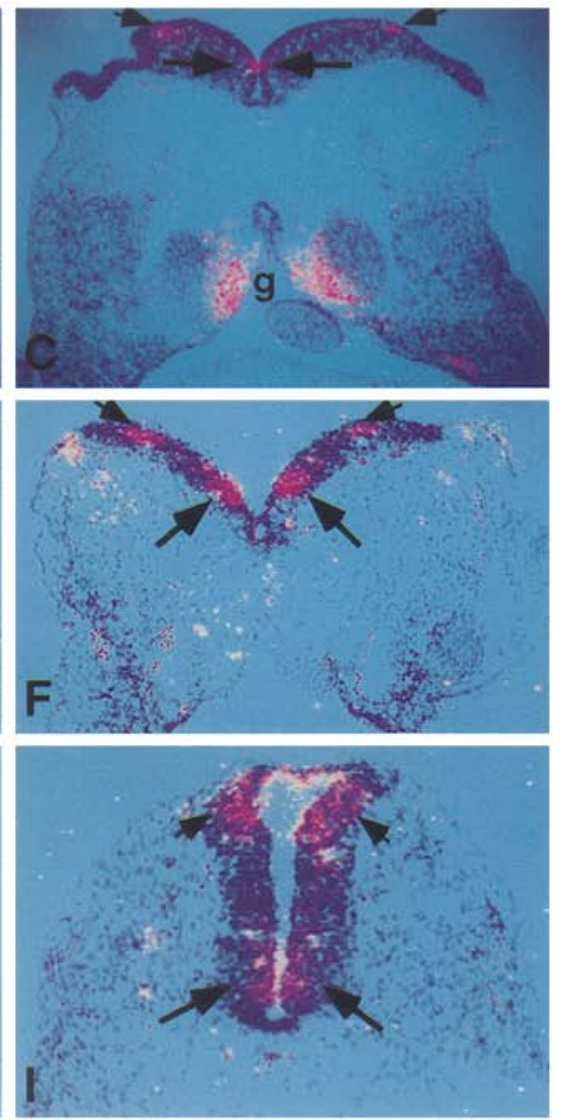

Figure 7. Ectopic expression of $S h$ in the dorsal CNS induces the expression of ptc in adjacent cells. Sections through the hindbrain $(A-F)$ and rostral spinal cord $(G-I)$ of 10.5 -dpc transgenic mouse embryos expressing chick Shh under the regulation of a Wnt-1 enhancer. Adjacent sections were hybridized with probes for mouse $S h h, H N F-3 \beta$ and $p t c$ as indicated. Normal expression of $H N F-3 \beta$, $S h h$, and ptc in the ventral CNS is indicated by large arrows. Ectopic activation of these genes in the dorsal CNS is indicated by small arrows. In addition to their CNS expression, $H N F-3 \beta$ and $S h$ are also normally expressed in the epithelium of the foregut (g) and ptc in the adjacent mesenchyme.

scriptional activation, thereby ensuring that Hh has its effects in limited regions. Misexpressed Hh causes severe pattern deformations in flies and mice (Echelard et al. 1993; Basler and Struhl 1994; Ingham and Fietz 1995), so it is clearly important to limit the action of the potent Hh protein.

The identification of this mouse ptc homolog helps unravel a key signaling pathway underlying induction and morphogenesis of many tissues and organs. The pathway appears to have several conserved components: the signal Hh, a target ptc, PKA, the zinc finger protein $\mathrm{Ci} / \mathrm{Gli}$, and TGF- $\beta$ targets such as $d p p$ in flies and Bone Morphogenetic Protein (BMP) genes in vertebrates. Although it is not yet known whether vertebrate Hh signals exert their effects by opposing Ptc function, the conservation of so many other features of the pathway makes this likely. In this case, we predict that lost ptc function in vertebrates will lead to ectopic expression of many $\mathrm{Hh}$ targets. Further experiments are under way to examine $p t c$ function in mice by removing and misexpressing the mouse ptc gene.

\section{Materials and methods}

Isolation of a ptc gene from the mouse

Two degenerate PCR primers [P4REV, GGACGAATTCYTNGANTGYTTYTGGGA; P22, CATACCAGCCAAGCTTGTCIGGCCARTGCAT (underline indicates cloning sequences)] were designed based on a comparison of Ptc amino acid sequences from fly (Drosophila melanogaster), mosquito (Anopheles gambiae), butterfly (Precis coenia), and beetle (Tribolium casteneum) (L. Goodrich, L. Nagy, R. Johnson, S. Carroll, and M. Scott, in prep.). P22 was used to reverse transcribe RNA from 12.5-dpc mouse limb bud (gift from Dr. D. Kingsley, Stanford University, CA / for $90 \mathrm{~min}$. at $37^{\circ} \mathrm{C}$. The cDNA was amplified with the P4REV and $\mathrm{P} 22$ primers with 35 cycles of $94^{\circ} \mathrm{C}$ for 15 sec; $50^{\circ} \mathrm{C}$ for $30 \mathrm{sec}$; and $72^{\circ} \mathrm{C}$ for $90 \mathrm{sec}$. PCR products of the expected size were subcloned into the TA vector (Invitrogen).

Using the cloned mouse PCR fragment as a probe, 300,000 plaques of a mouse 8.5-dpc $\lambda$ gt 10 cDNA library (a gift from Dr. B. Hogan, Vanderbilt University, Nashville, TN) were screened at $65^{\circ} \mathrm{C}(5 \times \mathrm{SSC}, 10 \%$ dextran sulfate, $5 \times$ Denhardt's solution, $200 \mathrm{mg} / \mathrm{ml}$ of sonicated salmon sperm DNA, $0.5 \%$ SDS) and washed in $2 \times$ SSC, $0.1 \%$ SDS, at room temperature. Seven 
Goodrich et al.

Figure 8. A possible topological model of the mouse Ptc protein. The mouse Ptc protein is proposed to have 12 TM domains and two glycosylated extracellular hydrophilic loops. Black and lightly shaded circles indicate identical and similar amino acids, respectively, shared between the mouse and fly Ptc proteins.

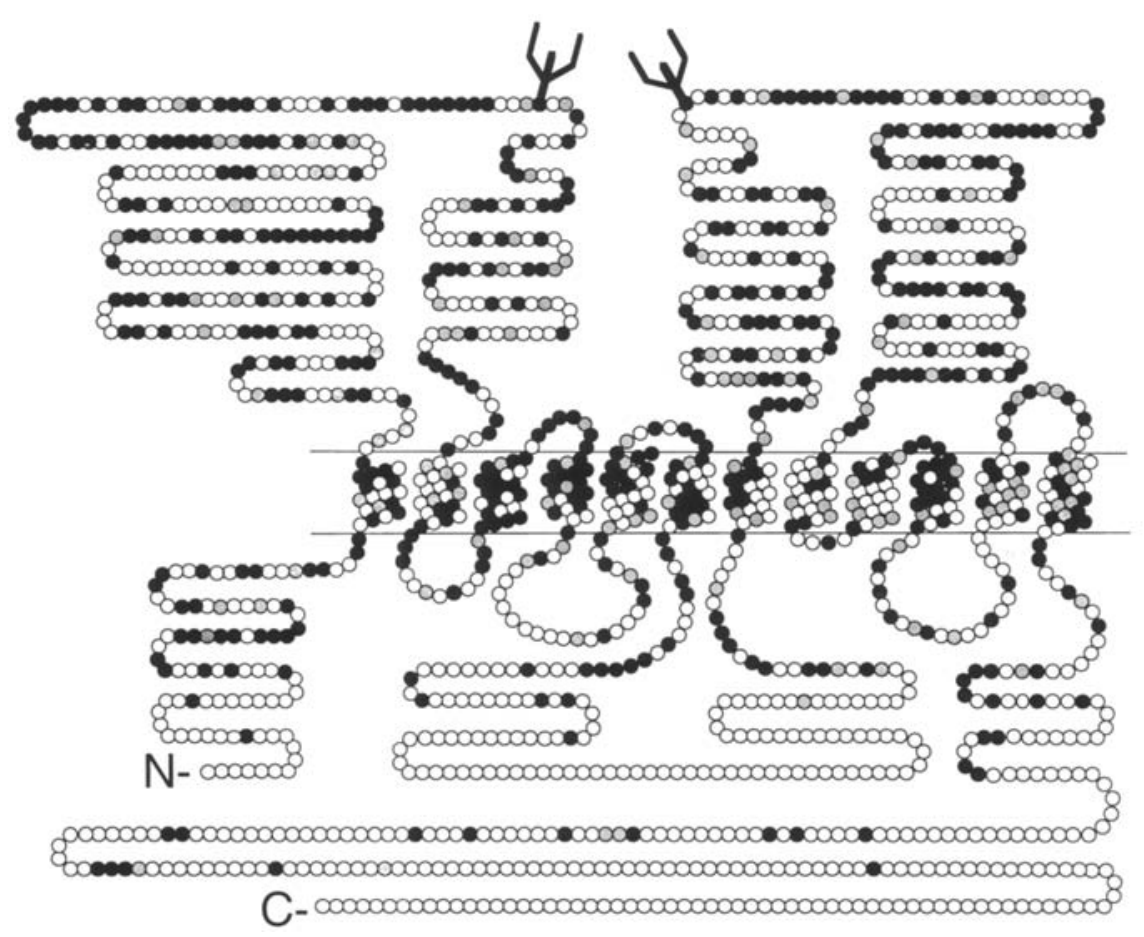

cDNAs (M1-M6, M8) were isolated. Then 200,000 plaques were rescreened using either a 1.1-kb EcoRI fragment from M2 or a mixed probe (XhoI fragment of $\mathrm{M} 2$ and the BamHI-BgIII fragment of M9) to isolate 11 additional clones (M9, M10, M12M15, M17-M21). Of the 18 isolated clones, 11 were subcloned into pBluescript II (Strategene). To determine the coding region of ptc, two clones, M2 and M9, were sequenced on both strands using dideoxy chain termination methods (Sanger et al. 1977). The sequence was analyzed using the MacVector and GCG programs.

\section{RNA blot hybridization}

A mouse embryonic RNA blot and an adult multiple tissue RNA blot (Clontech) were probed with a 900-bp EcoRI fragment from an amino-terminal coding region of $p t c$. Hybridization was performed at $65^{\circ} \mathrm{C}$ in $5 \times \mathrm{SSPE}, 10 \times$ Denhardt's solution, 100 $\mathrm{mg} / \mathrm{ml}$ of salmon sperm DNA, and $2 \%$ SDS. After several short washes at room temperature in $2 \times$ SSC, $0.05 \%$ SDS, the blots were washed at high stringency in $0.1 \times \mathrm{SSC}, 0.1 \% \mathrm{SDS}$, at $50^{\circ} \mathrm{C}$.

\section{Whole-mount in situ hybridization and sectioning}

Embryos (7.5 to 15.5 ) were obtained from superovulated FVB females mated to FVB males and staged as noon of the day of the plug as $0.5 \mathrm{dpc}$. $1 s t^{D}$ mutant mice were provided by Dr. P. Leder (Harvard Medical School, Boston, MA).

To detect ptc transcripts, the plasmid M2-3 (which contains the first $841 \mathrm{bp}$ of the cDNA clone M2) was linearized and transcribed with either $\mathrm{T} 3$ or $\mathrm{T} 7 \mathrm{RNA}$ polymerase to generate antisense or sense probes, using nonradioactive digoxigenin nucleotides (Boehringer Mannheim). To detect Shh and Ihh transcripts, antisense riboprobes were generated using Hh-14.1 and Hh-16.1 plasmids as templates (Echelard et al. 1993).

Whole-mount in situ hybridization was performed as described (Wilkinson 1992) but with the following modifications. Embryos were proteinase $\mathrm{K}$ digested for $6-20 \mathrm{~min}$ and pre- blocked for 2.5-3 hr. The posthybridization RNase digestion was omitted.

Whole-mount embryos were equilibrated in $50 \%$ sucrose in PBS at $4^{\circ} \mathrm{C}$ overnight and then dissected in sucrose and oriented in melted gelatin $17.5 \%$ gelatin, $15 \%$ sucrose, $0.05 \%$ sodium azide). After solidification, cubes containing the embryos were cut out, frozen on dry ice until opaque, and stored at $-80^{\circ} \mathrm{C}$. Sections $(20-25 \mathrm{~mm})$ were cut on a Hacker cryostat $\left(-20^{\circ} \mathrm{C}\right)$ and collected on slides coated with VectaBond (Vector Laboratories). The sections were dried on slides overnight and then soaked in PBS for at least $15 \mathrm{~min}$ before mounting in Aquamount (Lerner Laboratories). Sections were photographed on a Zeiss Axiophot microscope using Nomarski optics. Sections of Wnt1-Shh mice were prepared as described (Echelard et al. 1993). Slides of whole-mount in situs and sections were scanned and assembled using Adobe Photoshop with modification only of overall brightness and contrast.

\section{Acknowledgments}

We thank E. Storm and Drs. D. Kingsley, S. McConnell, N. O'Rourke, C. Tabin, and V. Marigo for valuable discussions and technical advice. Drs. D. Kingsley, V. Marigo, R. Nusse, and C. Tabin provided very helpful comments on the manuscript. We are grateful to D. Matthies and Dr. P. Beachy for help on primer design and Drs. S. Cordes and J. Rubenstein for helping with interpretation of the staining patterns. Libraries and templates for isolating insect and mouse ptc homologs were generously provided by Dr. R. Gwadz (Anopheles genomic DNA), D. Keyes, Dr. J. Williams, and Dr. S. Carroll (Precis caterpillars and cDNA library), Drs. S. Brown and R. Denell (Tribolium genomic library), Dr. D. Kingsley (mouse RNA), and Dr. B. Hogan (mouse cDNA library|. We thank Dr. P. Leder and A. Harrington for the $l s t^{D}$ mice. We thank Dr. Y. Echelard and A. McMahon for transgenic mice and support. L.V.G. was supported by a HHMI predoctoral fellowship, and R.L.J. was supported by the Cancer 
Research Fund of the Damon Runyon-Walter Winchell Foundation Fellowship, (DRG 1218). The research at Stanford was supported by HHMI. Work in the McMahon laboratory is supported by a grant from the National Institutes of Health.

The publication costs of this article were defrayed in part by payment of page charges. This article must therefore be hereby marked "advertisement" in accordance with 18 USC section 1734 solely to indicate this fact.

\section{Note added in proof}

The sequence data described in this paper have been submitted to the EMBL/GenBank data libraries under accession no. BankIt30589-V46155.

\section{References}

Basler, K. and G. Struhl. 1994. Compartment boundaries and the control of Drosophila limb pattern by hedgehog protein. $\mathrm{Na}$ ture 368: 208-214.

Bitgood, M.J. and A.P. McMahon. 1995. Hedgehog and Bmp genes are co-expressed at many diverse sites of cell-cell interaction in the mouse embryo. Dev. Biol. 172: 126-138.

Capdevila, J. and I. Guerrero. 1994. Targeted expression of the signaling molecule decapentaplegic induces pattern duplications and growth alterations in Drosophila wings. EMBO $\mathrm{f}$. 13: 4459-4468

Capdevila, J., M.P. Estrada, E. Sánchez-Herrero, and I. Guerrero. 1994a. The Drosophila segment polarity gene patched interacts with decapentaplegic in wing development. $E M B O F$. 13: $71-82$.

Capdevila, J., F. Pariente, I. Sampedro, J.L. Alonso, and I. Guerrero. 1994b. Subcellular localization of the segment polarity protein patched suggests an interaction with the wingless reception complex in Drosophila embryos. Development 120: $987-998$.

Chan, D.C., E. Laufer, C. Tabin, and P. Leder. 1995. Polydactylous limbs in Strong's Luxoid mice result from ectopic polarizing activity. Development 121: 1971-1978.

Chang, D.T., A. López, D.P. von Kessler, C. Chiang, B.K. Simandl, R. Zhao, M.F. Seldin, J.F. Fallon, and P.A. Beachy. 1994. Products, genetic linkage, and limb patterning activity of a murine hedgehog gene. Development 120: 3339-3353.

Doige, C.A. and G.F. Ames. 1993. ATP-dependent transport systems in bacteria and humans: Relevance to cystic fibrosis and multidrug resistance. Annu. Rev. Microbiol. 47: 291319.

Echelard, Y., D.J. Epstein, B. St-Jacques, L. Shen, J. Mohler, J.A. McMahon, and A.P. McMahon. 1993. Sonic hedgehog, a member of a family of putative secreted signaling molecules, is implicated in the regulation of CNS polarity. Cell 75: $1417-1430$.

Fan, C. and M. Tessier-Lavigne. 1994. Patterning of mammalian somites by surface ectoderm and notochord: Evidence for sclerotome induction by a hedgehog homolog. Cell 79: 1175-1186.

Fan, C., J.A. Porter, C. Chiang, D.T. Chang, P.A. Beachy, and M. Tessier-Lavigne. 1995. Long-range sclerotome induction by Sonic hedgehog: Direct role of the amino-terminal cleavage product and modulation by the cyclic AMP signaling pathway. Cell 81: 457-465.

Forbes, A.J., Y. Nakano, A.M. Taylor, and P.W. Ingham. 1993. Genetic analysis of hedgehog signalling in the Drosophila embryo. Development (Suppl.) 115-124.

Hall, T.M.T., J.A. Porter, P.A. Beachy, and D.J. Leahy. 1995. A potential catalytic site revealed by the 1.7 Á crystal structure of the amino-terminal signalling domain of Sonic hedgehog. Nature 378: 212-216.

Hidalgo, A. and P.W. Ingham. 1990. Cell patterning in the Drosophila segment: spatial regulation of the segment polarity gene patched. Development 110: 291-301.

Hooper, J.E. and M.P. Scott. 1989. The Drosophila patched gene encodes a putative membrane protein required for segmental patterning. Cell 59: 751-765.

Hubbard, S.C. and R.J. Ivatt. 1981. Synthesis and processing of asparagine-linked oligosaccharides. Annu. Rev. Biochem. 50: 555-583.

Hui, C., D. Slusarski, K. A. Platt, R. Holmgren, and A.L. Joyner. 1994. Expression of three mouse homologs of the Drosophila segment polarity gene cubitus interruptus, Gli, Gli-2, and Gli-3, in ectoderm- and mesoderm-derived tissues suggests multiple roles during postimplantation development. Dev. Biol. 162: 402-413.

Hynes, M., J.A. Porter, C. Chiang, D. Chang, M. Tessier-Lavigne, P.A. Beachy, and A. Rosenthal. 1995. Induction of midbrain dopaminergic neurons by Sonic hedeghog. Neuron 15: 35-44.

Ingham, P.W. 1993. Localized hedgehog activity controls spatial limits of wingless transcription in the Drosophila embryo. Nature 366: 560-562.

Ingham, P.W. and M.J. Fietz. 1995. Quantitative effects of hedgehog and decapentaplegic activity on the patterning of the Drosophila wing. Curr. Biol. 5: 432-440.

Ingham, P.W., A.M. Taylor, and Y. Nakano. 1991. Role of the Drosophila patched gene in positional signalling. Nature 353: 184-87.

Jiang, J. and G. Struhl. 1995. Protein kinase A and hedgehog signaling in Drosophila limb development. Cell 80: 563-572.

Johnson, R.L., E. Laufer, R.D. Riddle, and C.J. Tabin. 1994. Ectopic expression of Sonic hedgehog alters dorsal-ventral patterning of somites. Cell 79: 1165-1173.

Johnson, R.L., J.K. Grenier, and M.P. Scott. 1995. patched overexpression alters wing disc size and pattern: Transcriptional and post-transcriptional effects on hedgehog targets. Development 121: 4161-4170.

Kingsley, D.M. 1994. The TGF- $\beta$ superfamily: New members, new receptors, and new genetic tests of function in different organisms. Genes \& Dev. 8: 133-146.

Kinzler, K.W. and B. Vogelstein. 1990. The GLI gene encodes a nuclear protein which binds specific sequences in the human genome. Mol. Cell. Biology 10: 634-642.

Kinzler, K.W., J.M. Ruppert, S.H. Bigner, and B. Vogelstein. 1988. The GLI gene is a member of the Krúppel family of zinc finger proteins. Nature 332: 371-374.

Kozak, M. 1991. An analysis of vertebrate mRNA sequences: Intimations of translational control. J. Cell Biol. 115: 887903.

Krauss, S., J.-P. Concordet, and P.W. Ingham. 1993. A functionally conserved homolog of the Drosophila segment polarity gene $h h$ is expressed in tissues with polarizing activity in zebrafish embryos. Cell 75: 1431-1444.

Kyte, J. and R.F. Doolittle. 1982. A simple method for displaying the hydropathic character of a protein. J. Mol. Biol. 157: 105132.

Lee, J.J., D.P. von Kessler, S. Parks, and P.A. Beachy. 1992. Secretion and localized transcription suggest a role in positional signaling for products of the segmentation gene hedgehog. Cell 71: 33-50.

Lee, J.J., S.C. Ekker, D.P. von Kessler, J.A. Porter, B.I. Sun, and P.A. Beachy. 1994. Autoproteolysis in hedgehog protein biogenesis. Science 266: 1528-1537. 
Lepage, T., S.M. Cohen, F.J. Diaz-Benjumea, and S.M. Parkhurst. 1995. Signal transduction by cAMP-dependent protein kinase A in Drosophila limb patterning. Nature 373: 711-715.

Li, W., J.T. Ohlmeyer, M.E. Lane, and D. Kalderon. 1995. Function of protein kinase $A$ in hedgehog signal transduction and Drosophila imaginal disc development. Cell 80: 553-562.

Marigo, V., M.P. Scott, R.L. Johnson, L.V. Goodrich, and C.J. Tabin. 1996. Conservation in hedgehog signaling: Induction of a chicken patched homolog by sonic hedgehog in the developing limb. Development (in press).

Martinez-Arias, A., N.E. Baker, and P.W. Ingham. 1988. Role of segment polarity genes in the definition and maintenance of cell states in the Drosophila embryo. Development 103: $157-170$.

McMahon, A.P., A.L. Joyner, A. Bradley, and J.A. McMahon. 1992. The midbrain-hindbrain phenotype of Wnt-1-/Wnt-1mice results from stepwise deletion of engrailed-expressing cells by 9.5 days postcoitum. Cell 69: 581-595.

Mohler, J. and K. Vani. 1992. Molecular organization and embryonic expression of the hedgehog gene involved in cell-cell communication in segmental patterning of Drosophila. Development 115: 957-971.

Motzny, C.K. and R. Holmgren. 1995. The Drosophila cubitus interruptus protein and its role in the wingless and hedgehog signal transduction pathways. Mech. Dev. 52: 137-150.

Nakano, Y., I. Guerrero, A. Hidalgo, A. Taylor, J.R.S. Whittle, and P.W. Ingham. 1989. A protein with several possible membrane-spanning domains encoded by the Drosophila segment polarity gene patched. Nature 341: 508-513.

Nusse, R. and H. Varmus. 1992. Wnt genes. Cell 69: 1073-1087.

Orenic, T.V., D.C. Slusarski, K.L. Kroll, and R.A. Holmgren. 1990. Cloning and characterization of the segment polarity gene cubitus interruptus Dominant of Drosophila. Genes \& Dev. 4: 1053-1067.

Pan, D. and G.M. Rubin. 1995. cAMP-dependent protein kinase and hedgehog act antagonistically in regulating decapentaplegic transcription in Drosophila imaginal discs. Cell 80: $543-552$.

Placzek, M., M. Tessier-Lavigne, T. Yamada, T. Jessell, and J. Dodd. 1990. Mesodermal control of neural cell identity: Floor plate induction by the notochord. Science 250: 985988.

Placzek, M., T. Yamada, M. Tessier-Lavigne, T. Jessell, and J. Dodd. 1991. Control of dorsoventral pattern in vertebrate neural development: induction and polarizing properties of the floor plate. Development (Suppl.) 2: 105-122.

Pourquié O., M. Coltey, M. Teillet, C. Ordahl, and N.M. Le Douarin. 1993. Control of dorsoventral patterning of somitic derivatives by notochord and floor plate. Proc. Nat. Acad. Sci. 90: 5242-5246.

Puelles, L. and J.L.R. Rubenstein. 1993. Expression patterns of homeobox and other putative regulatory genes in the embryonic mouse forebrain suggest a neuromeric organization. Trends Neurosci. 16: 472-479.

Riddle, R.D., R.L. Johnson, E. Laufer, and C. Tabin. 1993. Sonic hedgehog mediates the polarizing activity of the ZPA. Cell 75: 1401-1416.

Roelink, H., A. Augsburger, J. Heemskerk, V. Korzh, S. Norlin, A. Ruiz i Altaba, Y. Tanabe, M. Placzek, T. Edlund, T.M. Jessell, and J. Dodd. 1994. Floor plate and motor neuron induction by whh-1, a vertebrate homolog of hedgehog expressed by the notochord. Cell 76: 761-775.

Roelink, H., J.A. Porter, C. Chiang, Y. Tanabe, D.T. Chang, P.A. Beachy, and T.M. Jessell. 1995. Floor plate and motor neuron induction by different concentrations of the amino-terminal cleavage product of Sonic hedgehog autoproteolysis. Cell 81: 445-455.

Saier, M.H. 1994. Convergence and divergence in the evolution of transport proteins. BioEssays 16: 23-29.

Sampedro, J. and I. Guerrero. 1991. Unrestricted expression of the Drosophila gene patched allows a normal segment polarity. Nature 353: 187-190.

Sanger, F., S. Nicklen, and A.R. Coulson. 1977. DNA sequencing with chain-terminating inhibitors. Proc. Natl. Acad. Sci. 74: 5463-5467.

Saunders, J.W. and M.T. Gasseling. 1968. Ectodermal-mesenchymal interactions in the origin of limb symmetry. In Epithelial-mesenchymal interactions (ed. R. Fleischmajer, and R.E. Billinghams), pp. 78-97. Williams and Wilkins, Baltimore, MD.

Schuske, K., J.E. Hooper, and M.P. Scott. 1994. patched overexpression causes loss of wingless expression in Drosophila embryos. Dev. Biol. 164: 300-311.

Slusarski, D.C., C.K. Motzny, and R. Holmgren. 1995. Mutations that alter the timing and pattern of cubitus interruptus expression in Drosophila melanogaster. Genetics 139: 229240.

Strutt, D.I., V. Wiersdorff, and M. Mlodzik. 1995. Regulation of furrow progression in the Drosophila eye by cAMP-dependent protein kinase A. Nature 373: 705-709.

Summerbell, D. 1974. A quantitative analysis of the effect of excision of the AER from the chick limb-bud. J. Embryol. Exp. Morphol. 32: 651-660.

Tabata, T. and T. Kornberg. 1994. Hedgehog is a signaling protein with a key role in patterning Drosophila imaginal discs. Cell 76: 89-102.

Tabata, T., S. Eaton, and T.B. Kornberg. 1992. The Drosophila hedgehog gene is expressed specifically in posterior compartment cells and is a target of engrailed regulation. Genes \& Dev. 6: 2635-2645.

Taylor, A.M., Y. Nakano, J. Mohler, and P.W. Ingham. 1993. Contrasting distributions of patched and hedgehog proteins in the Drosophila embryo. Mech. Devel. 42: 89-96.

Tessier-Lavigne, M., M. Placzek, A.G.S. Lumsden, J. Dodd, and T.M. Jessell. 1988. Chemotropic guidance of developing axons in the mammalian central nervous system. Nature 336: 775-778.

Wilkinson, D.G. 1992. Whole mount in situ hybridization of vertebrate embryos. In In situ hybridization: A practical approach (ed. D.G. Wilkinson), pp. 75-83. Oxford University Press, New York, NY. 


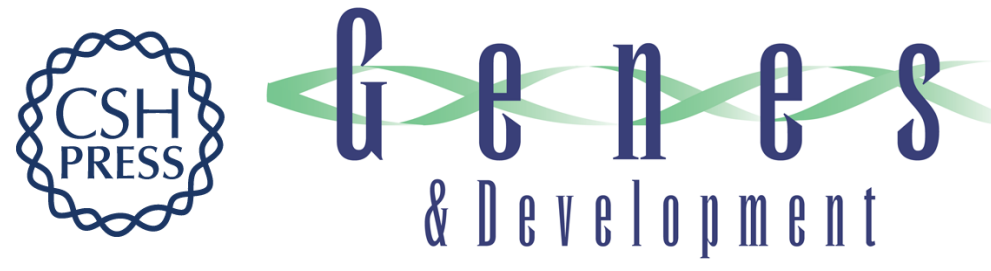

\section{Conservation of the hedgehog/patched signaling pathway from flies to mice: induction of a mouse patched gene by Hedgehog.}

L V Goodrich, R L Johnson, L Milenkovic, et al.

Genes Dev. 1996, 10:

Access the most recent version at doi:10.1101/gad.10.3.301

References This article cites 59 articles, 17 of which can be accessed free at: http://genesdev.cshlp.org/content/10/3/301.full.html\#ref-list-1

License

Email Alerting

Service

Receive free email alerts when new articles cite this article - sign up in the box at the top right corner of the article or click here.

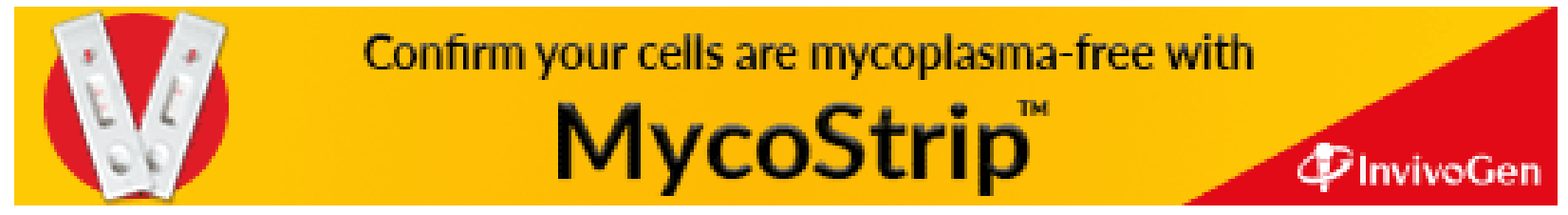

